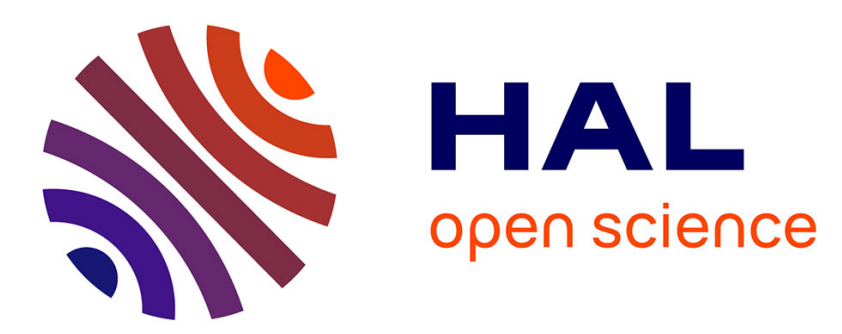

\title{
APD photodetectors in the Geiger photon counter mode.
}

Denis Pellion, K. Jradi, F. Moutier, F. Oms, C. Magenc, Daniel Estève, A.R. Bazer-Bachi, Thierry Camps

\section{- To cite this version:}

Denis Pellion, K. Jradi, F. Moutier, F. Oms, C. Magenc, et al.. APD photodetectors in the Geiger photon counter mode.. Nuclear Instruments and Methods in Physics Research, 2009, A 610 (1), p. 410-414. 10.1016/j.nima.2009.05.180 . hal-00637352

\section{HAL Id: hal-00637352 https://hal.science/hal-00637352}

Submitted on 7 Nov 2011

HAL is a multi-disciplinary open access archive for the deposit and dissemination of scientific research documents, whether they are published or not. The documents may come from teaching and research institutions in France or abroad, or from public or private research centers.
L'archive ouverte pluridisciplinaire $\mathbf{H A L}$, est destinée au dépôt et à la diffusion de documents scientifiques de niveau recherche, publiés ou non, émanant des établissements d'enseignement et de recherche français ou étrangers, des laboratoires publics ou privés. 


\title{
APD photodetectors in the Geiger photon counter mode
}

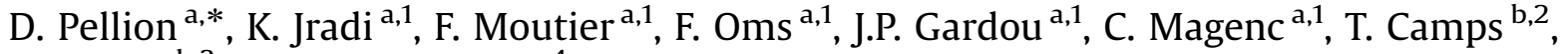 \\ D. Esteve ${ }^{\text {b,3 }}$, A.R. Bazer-Bachi ${ }^{\text {a }} 4$ \\ a Centre d'Etude Spatiale des Rayonnements, CNRS/UPS (GIATHE), UMR5187, 9 avenue du Colonel Roche, Boite postale 4346, 31028 Toulouse Cedex 4, France \\ ${ }^{\mathrm{b}}$ Laboratoire d'Analyse et d'Architecture des Systèmes du CNRS, UPR8000, 7 avenue du Colonel Roche, 31077 Toulouse Cedex 4, France
}

\section{A R T I C L E I N F O}

Available online 2 June 2009

Keywords:

SiPM

APD Geiger

Photon counting

Modelization

\begin{abstract}
A B S T R A C T
Geiger APD technology, which has been used for a few years now [[8] R.H. Haitz, J. Appl. Phys. 35 (5) (1964) 1370], is evolving towards better performances, including integration in multifunctional microsystems; one such achievement today is the so-called SiPM [[1] P. Buzhan, et al., Nucl. Instr. and Meth. A 567 (2006) 78]. The present work has been conducted by a consortium of researchers from CESR and LAAS/CNRS and the manufacturing of components was achieved in the clean room of LAAS/CNRS.

We present here an original N/P technology of photodiode, designed so as to offer a very good homogeneity in the electrical operating characteristics. For this, we have chosen a design and technological process that defines the breakdown voltage from the substrate doping.

We present the technological process we developed, in which we took special care to maintain, by low transit temperature processes, at the highest quality level the initial characteristics of the materials.

We will also present the performances of the diodes produced, with sizes ranging from 10 to $100 \mu \mathrm{m}$, as a function of many parameters (gain, dark current, etc). We also produced SiPM, and also $8 \times 8$ arrays of SiPM.

Typical characteristics for a single diode are a $V_{\mathrm{br}}$ between 43 and $44 \mathrm{~V}$, and a dark current below $1 \mathrm{pA}$ at ambient temperature. But the most important feature seems to be the high homogeneity of these performances all over the wafer surface. This gives us great confidence in the next step of our work, which is the manufacturing of very high-sensitivity imaging devices.
\end{abstract}

(c) 2009 Elsevier B.V. All rights reserved.

\section{Introduction}

Very high energy (VHE) gamma-rays are usually detected by the faint flash of light, a few nanoseconds long, which are generated while crossing the earth's atmosphere. This flash of visible light is due to the Cherenkov effect of ultra relativistic particles composing the cosmic ray flux. For two decades now, dedicated telescopes have been designed and constructed to explore this field. They use a large mirror to concentrate the light on a detection plane, usually made of hundreds or thousands of photomultipliers. The associated electronics is used to trigger the system and collect information on the energy of the shower, its

\footnotetext{
* Corresponding author. Tel.: +3305 615566 66, +33 5615575 69; fax: +330561556701.

E-mail addresses: pellion@hotmail.fr (D. Pellion), esteve@laas.fr (D. Esteve), bazer@cesr.fr (A.R. Bazer-Bachi).

${ }^{1}$ Tel.: +3305615566 66; fax: +330561556701.

2 Tel.: +3305613362 00; fax: +330561553577.

3 Tel.: +330561336200, +330561336403; fax: +330561553577.

${ }^{4}$ Tel.: +3305615566 66, +3305622582 70; fax: +330561556701.
}

tridimensional shape, and eventually the nature of the primary particle (photon or hadron) hitting the top of the atmosphere. This is made possible because of the imaging capacity given by the use of a large number of pixels.

Today, the only photodetector available, well suited for this use, is the PM tube, which means that the smallest size of the pixel is around $1 \mathrm{~cm}$. It implies that a current VHE telescope, such as Hess-II for instance, with 2000 PMT will be huge to say the least.

Will future VHE cameras follow this standard scheme? Not necessarily so. A few years ago, we started R\&D work to find an alternative to the basic PMT detector using solid state detectors, with the aim of drastically reducing the size and cost of future Cherenkov cameras, while of course maintaining or increasing the detection capability. Today, the technology of silicon PM (SiPM) may make this possible and our aim in this work is to manufacture an "on the chip" Cherenkov camera. All the details given in this paper are used for the design of a $64 \times 64$ detector (4096 pixels) with a decimetric size. We report here the results and performances of the Geiger APD we have developed as well as those of the SiPM using them and finally those of our $8 \times 8$ imager (64 pixels) available today. The most challenging part of this work 
has been to maintain a high uniformity of the response all along the wafer processing to offer true imaging capacity.

This work was initiated with the astrophysical applications in mind. Of course, now mastering the SiPM technology, we have also undertaken application works in the biological and medical fields.

We will present below the simulations used for the design of our detectors and the various results obtained. Future works will be mentioned.

\section{Technological constraints of the Geiger mode, structure chosen, simulation and presentation of the process}

The detectors in Geiger mode are of recent design, although the principle was proposed in the 1970s [2]. It consists in polarizing, in a transitory way, a p-n junction functioning in the zone of very strong multiplication. The capture of a photon results in an important impulse of current, from $10^{6}$ to $10^{8}$ electrons, delivered in a few nanoseconds [3]. The performance is considerable but it generates thermal noise effects of carriers, which enter in competition with the incidental photons.

The proposal of Buzhan et al. [4] to use a large number of Geiger photodiodes in parallel in order to have a single detector (SiPM) of a large area of detection $\left(>1 \mathrm{~mm}^{2}\right)$ with least possible noise caused an important movement for research to design and manufacture such devices. Some first encouraging results exist [5-7], which will have important evolutions in performances to reduce the noise and to adapt the design to the needs for detection.

Our objective in launching this program was to define a design and a process that optimizes the levels of noises and the homogeneity of the devices to, later, manufacture a detector matrix with imaging capacity.

We have made a technological choice to ensure great homogeneity and to obtain an identical gain and comparable performances from one photodiode to another. To ensure this homogeneity we made the choice to use the doping of the substrate and not a surimplantation $\mathrm{p}+$ to define the operating voltage of the components. Indeed this structure guarantees a better homogeneity of the breakdown voltage because the doping of the substrate is more homogeneous than a doping carried out by ionic implantation. The cathode of the photodiode is made by an implantation $\mathrm{N}^{++}$(Arsenic) strongly doped (10 times more than the substrate). The p-doped substrate (Boron) forms the common anode.

To avoid border effects, and a premature breakdown, we made the technological choice to create guard rings $N$, slightly doped and deep.

The simulation of the technological process makes it possible to check the breakdown voltages of the various junctions and to validate technological choices (doses, dopings, temperature, duration of annealings, etc.). Our technological process was first simulated by a two-dimensional Silvaco software simulation (cf. Fig. 1).

A simulation of the static electrical behaviour of the devices was carried out to validate the breakdown voltage and leakage currents (Fig. 2).

\section{Results}

\subsection{Validation of the guard ring}

The electrical characteristics of the junctions enable us to validate the voltage behaviour of the strongly implanted area.

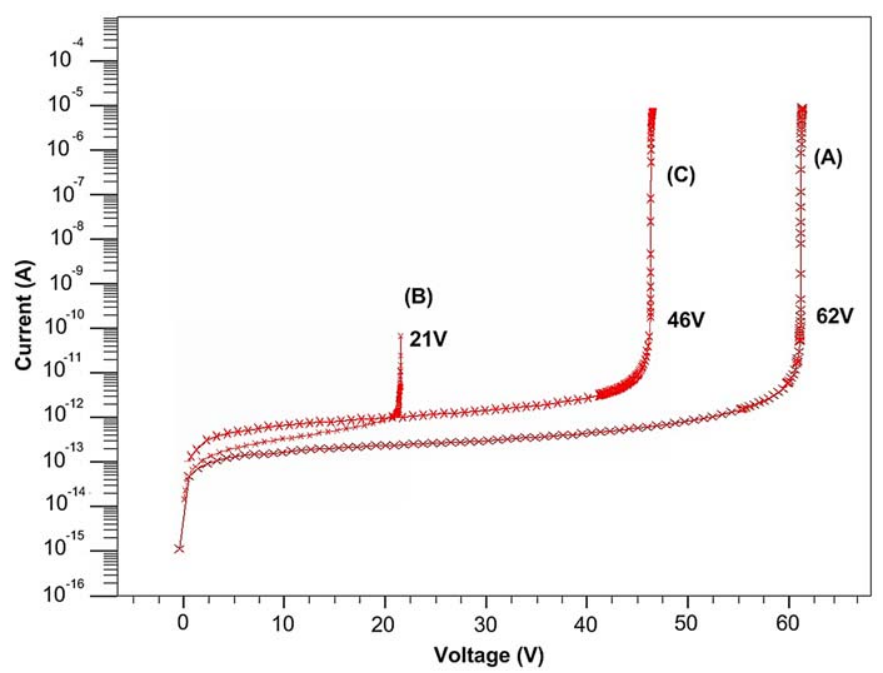

Fig. 2. Simulation of $I(V)$ characteristics of the guard ring $\mathrm{N}^{-}$alone $(\mathrm{A})$, of the $\mathrm{N}^{++}$ area corresponding to the detection zone (B), and of the complete structure (C).

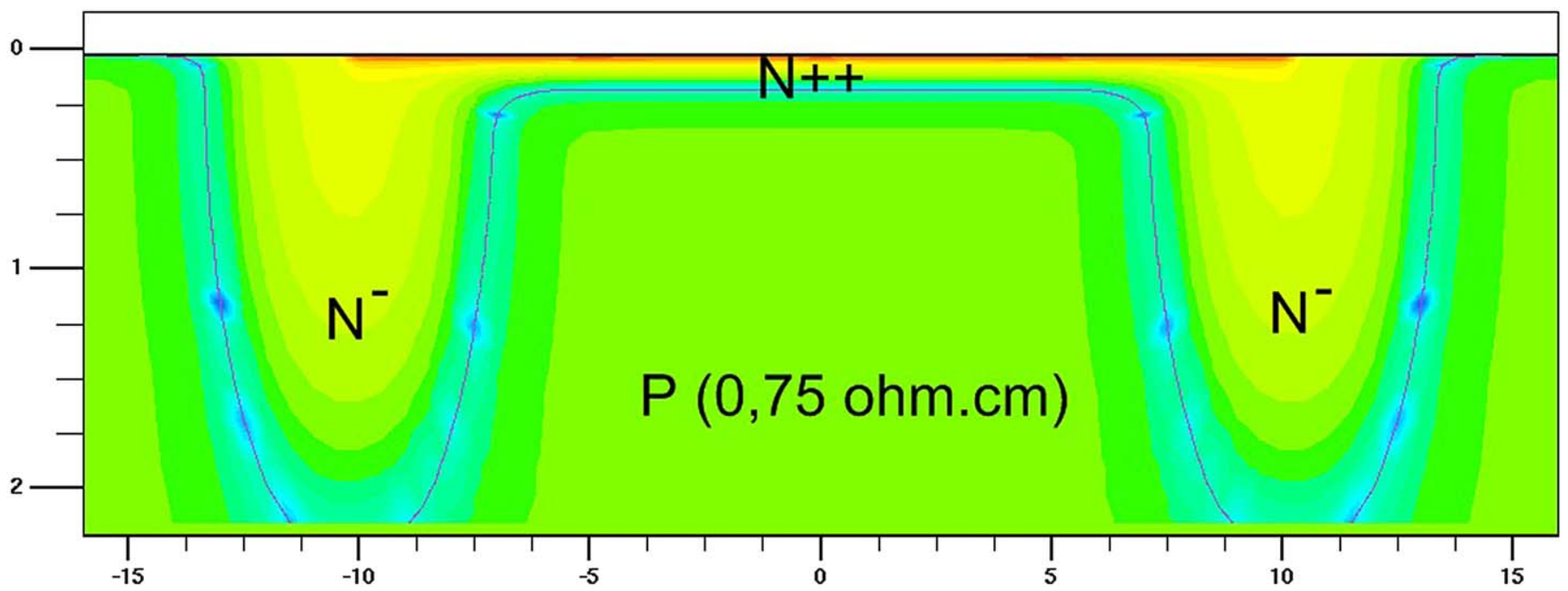

Fig. 1. Simulation of the structure 


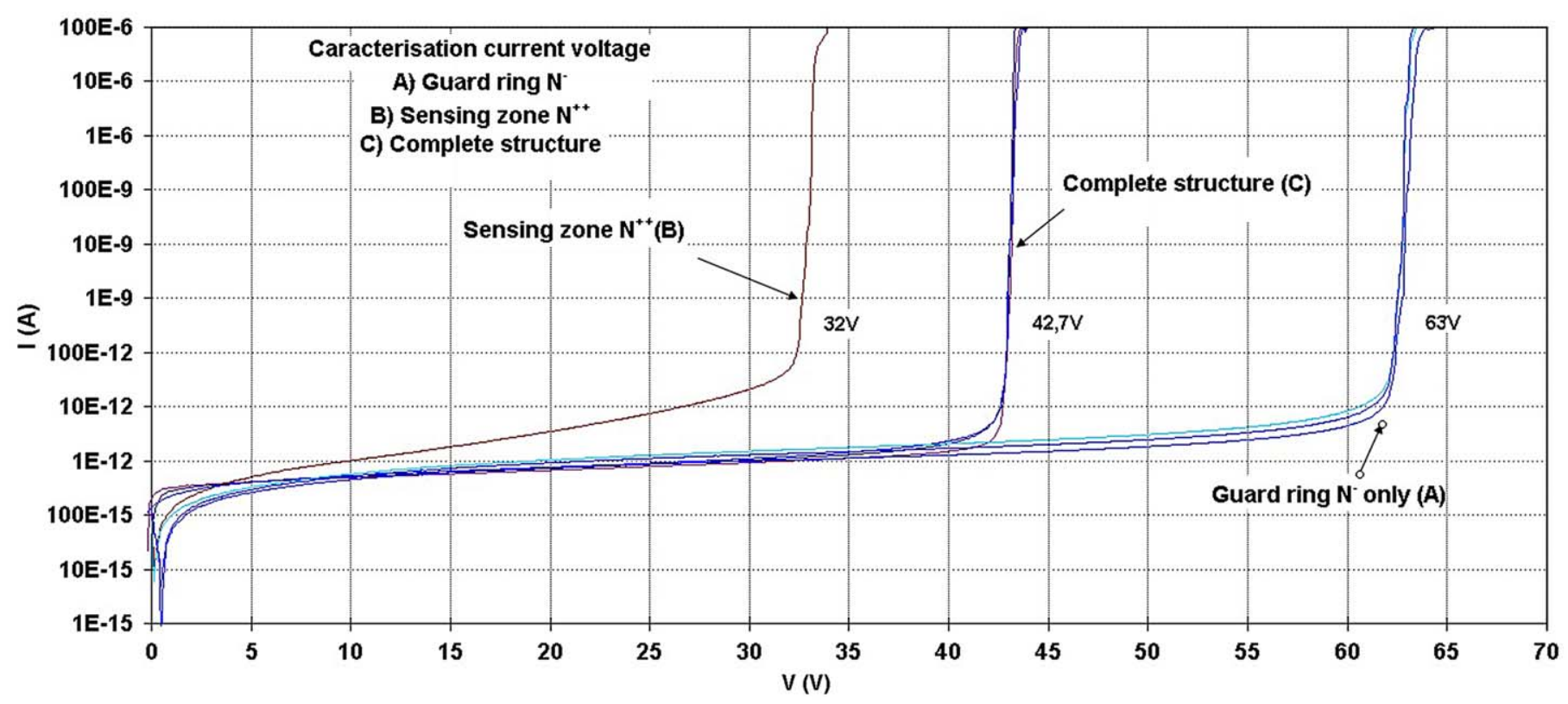

Fig. 3. $I(V)$ characteristics measured for the guard ring $\mathrm{N}^{-}(\mathrm{A})$, the $\mathrm{N}^{++}$area (B), and the complete structure (C).

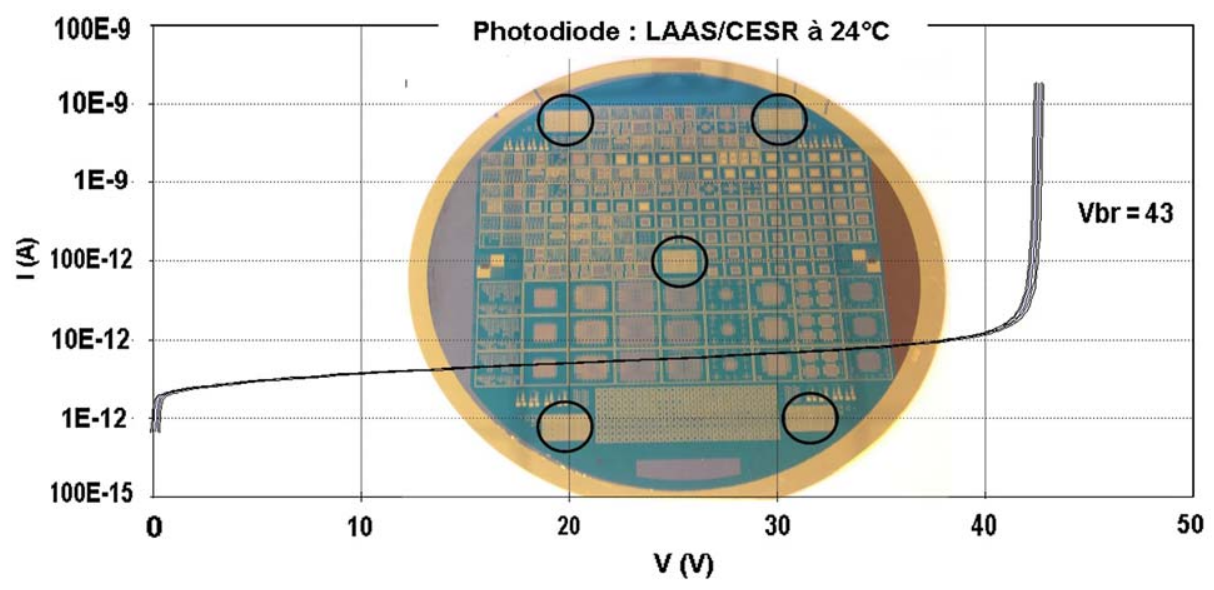

Fig. 4. The 5 test structures on the 4 in. wafer and $I(V)$ Characteristics for 5 photodiodes, with $100 \mu$ m diameter.

Fig. 3 shows the expected breakdown voltages for the Geiger mode and the leakage current, in conformity with the simulations carried out.

\subsection{Evaluation of the homogeneity of the breakdown voltage}

In the Geiger mode, to have comparable performances (gain, dark count rates, quantum efficiency) of a photodiode with respect to another, the control of the breakdown voltage is a stake for the scientific community. Indeed to make imagery in the Geiger mode the photodiodes must have identical breakdown voltages, and the supply voltage could be common, which would simplify the control circuit. Fig. 4 shows the wafer at the end of the process, with the five zones of tests separated by $50 \mu \mathrm{m}$, which we have defined. In these zones of tests we have photodiodes of different sizes, from 10 to $100 \mu \mathrm{m}$ diameter, allowing us to validate the homogeneity of the breakdown voltages.

The measurement of the breakdown voltage was carried out in static $I(V)$ mode as shown in Fig. 4: $V_{\mathrm{br}}=42.7 \mathrm{~V} \pm 250 \mathrm{mV}$.
We tested it on a large-area device: $3200 \times 3700 \mu \mathrm{m}^{2}$, corresponding to an imager made up of 64 SiPM of 64 photodiodes of $25 \mu \mathrm{m}$ side each (Fig. 5).

On those devices, we note in Fig. 6 (zoom on voltage) the comparablygood homogeneity $\left(\Delta V=400 \mathrm{mV} / 12 \mathrm{~mm}^{2}\right)$ of the breakdown voltage of the whole array of SiPM.

\subsection{Evaluation of thermal noise: dark count rate (DCR)}

We measured thermal noise in the Geiger mode at the temperature of $22^{\circ} \mathrm{C}$ (Fig. 7). The Geiger pulses begin to be visible starting from $\sim 43 \mathrm{~V}$. In Fig. 7 , the voltage of photodiodes is adjusted between 43 and $49 \mathrm{~V}$. From $13 \%$ beyond the avalanche we have a gain of $1 \times 10^{6}$ electrons.

\section{Conclusion}

We have reported in this paper our work on Geiger APDs: the design, the manufacturing and the testing. It has been a lengthy 


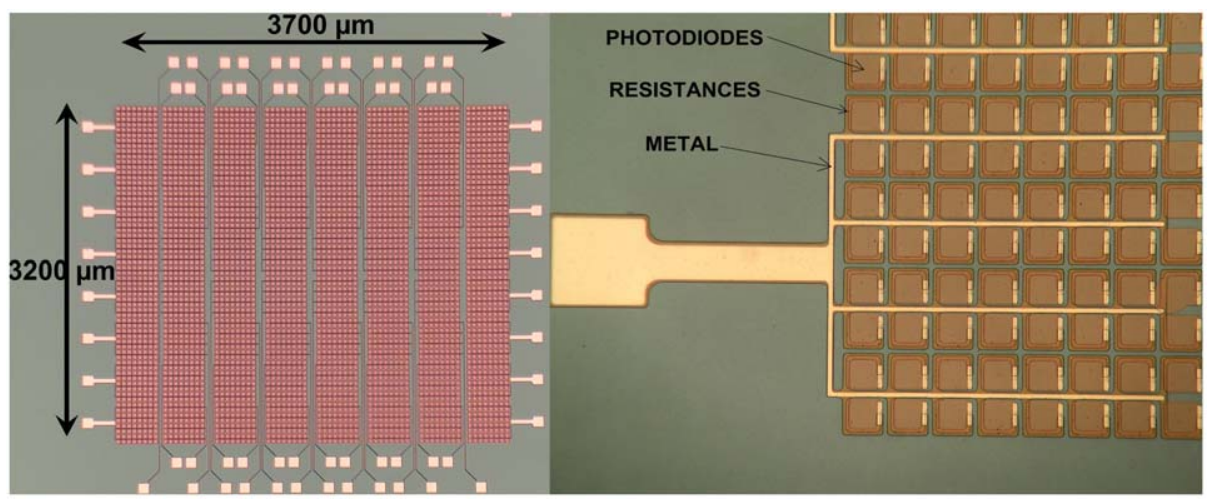

Fig. 5. Picture of a 64-SiPM imager, recorded with 10X \& 20X optical microscopes.

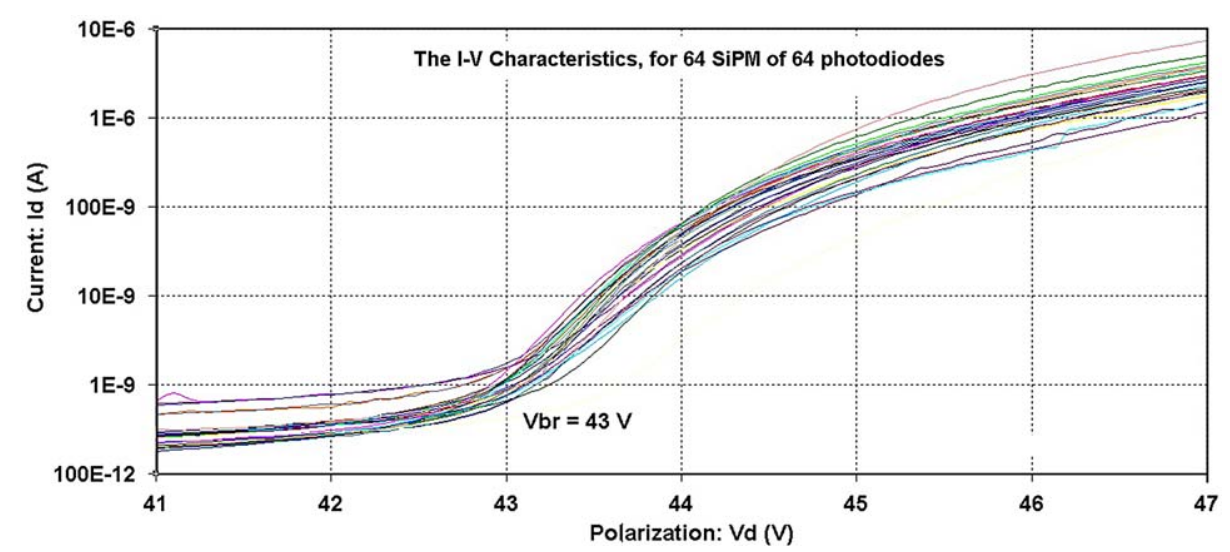

Fig. 6. $I(V)$ characteristics for the 64 SiPM array (with resistance).

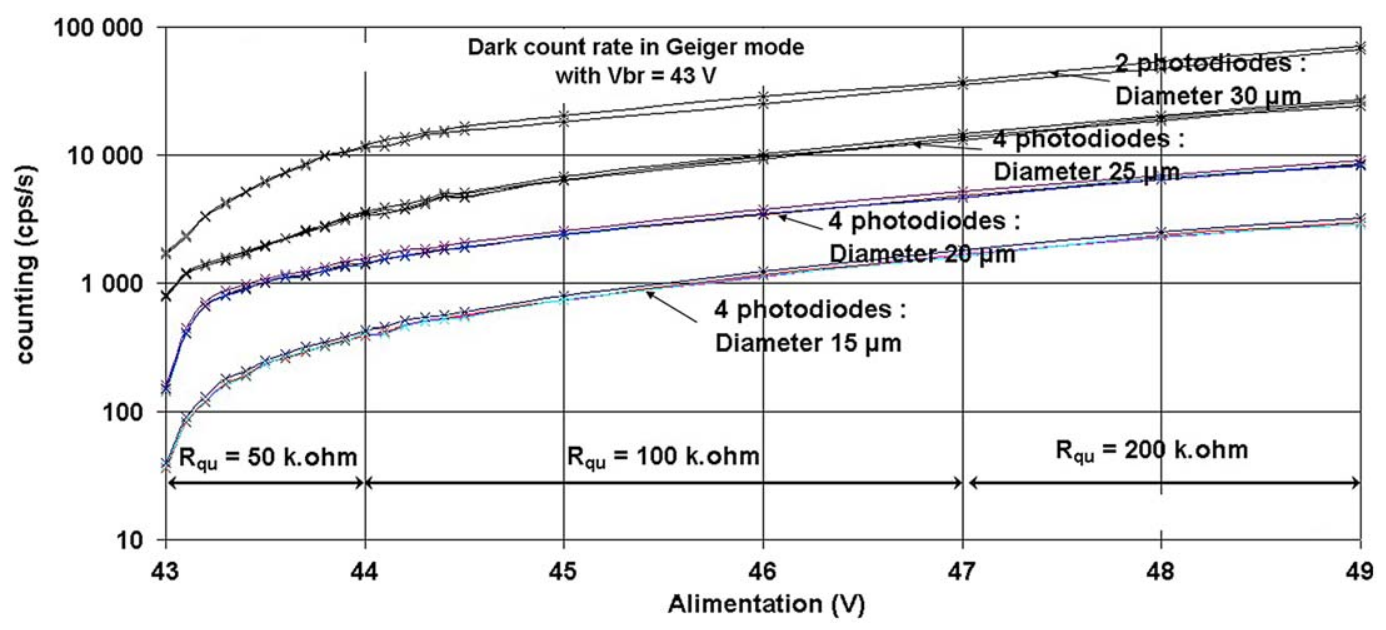

Fig. 7. Dark count rates in Geiger mode.

technological procedure and we had to take a number of technological choices. It seems now these choices have been reasonable, as the overall performances are quite acceptable. In particular, the uniformity of the response all over the wafer surface is, today, the most promising result.

Our future work will continue in two directions. The first one will be the development of arrays of SiPM. It was not mentioned here, but it is obvious that a detector must be associated with a front-end electronics, and an analyzing system. Each application (in biology, medicine and astrophysics) must be specifically tailored to the needs. So, the number of cells in a SiPM and the size of the elementary cell can vary with the application. Furthermore, size of an array is limited for us today to 64 $(8 \times 8)$. But this will of course increase, one problem being the increasing size of the associated electronics.

In this respect, for VHE applications, we know solid state Cherenkov astronomy can work, thanks to our preliminary work at Pic du Midi [9], and the work of the Magic collaboration [10]. So, we are working on a demonstrator for a solid state Cherenkov telescope, which will be installed atop Pic du Midi ( $2870 \mathrm{~m}$ in the French Pyrénées). The camera will comprise 512 pixels, using our optimized SiPM, and will include microlenses to improve photon 
collection, dedicated 64 channel ASIC and a $4 \mathrm{~m}$ motorized mirror. We plan to see the Crab nebula during the 2009 winter.

Our second line of work will be the design and manufacturing of high-resolution Geiger imaging systems. We have shown that we can have a high uniformity over the wafer surface. This allows building Geiger imagers in the megapixel range, of course, with many problems in the design of addressing and reading of the cells. The speed of image taking is planned to be in the $\mathrm{KHz}$ range.

\section{Acknowledgments}

This work was supported by Conseil Régional Midi-Pyrénées. The technological achievements were made possible thanks to the help of "Centrale de Technologie du LAAS/CNRS", to whom we are very grateful, in the frame of the RTB procedure of the French Ministry of Education and Research.

\section{References}

[1] P. Buzhan, et al., Nucl. Instr. and Meth. A567 (2006) 78

[2] R.H. Haitz, et al., J. Appl. Phys. 35 (5) (1965) 1370.

[3] S. Cova, M. Ghioni, A. Lacaita, C. Samori, F. Zappa, Appl. Opt. 35 (12) (1996) 1956.

[4] P. Buzhan, et al., Nucl. Instr. and Meth. A504 (2003) 48

[5] B.F. Aull, Geiger-mode avalanche photodiode arrays for imaging laser radar, Solid State Research Report, Lincoln Laboratory, March 1997, pp. 31-33.

[6] F. Zappa, A. Gulinatti, P. Maccagnani, S. Tisa, S. Cova, IEEE Photon. Technol. Lett. 17 (3) (2005) 657.

[7] A. Rochas, M. Gani, B. Furrer, G. Ribordy, P.A. Besse, N. Gisin, R.S. Popovic, Rev. Sci. Instrum. 74 (2003) 3263.

[8] R.H. Haitz, J. Appl. Phys. 35 (5) (1964) 1370.

[9] D. Pellion, et al., Geiger Avalanche Photodiodes as tentative light detectors for VHE gamma ray astronomy, Exp. Astron., accepted for publication.

[10] A. Biland, et al., Nucl. Instr. and Meth. A595 (2008) 165. 